\title{
LA DEMOCRACIA QUE TUVIMOS, LA DEMOCRACIA QUE NO FUE.
}

\author{
Sofía Correa Sutil
}

La discusión que se realiza en nuestros días sobre la transición a la democracia ha carecido en general de una mirada histórica que explique cómo fue en la práctica la democracia chilena antes del golpe de estado. Si bien durante la dictadura se la tendió a idealizar, hablándose en algunos casos de 150 años de democracia ininterrumpida, no olvidemos que años antes no pocos caracterizaron el sistema político vigente en el país como el de una democracia formal que debía ser transformada radicalmente.

Ni tanto ni tan poco. Y si bien el tipo ideal de democracia no se da en la práctica en ningún lugar, es de enorme interés analizar cuáles fueron las limitaciones y virtudes del muy particular régimen democrático que rigió en Chile con la Constitución de 1925.

Despejemos por de pronto aquello de los 150 años de democracia. Tan sólo tomando en consideración la continuidad institucional, no llegamos a tener nunca un período de al menos 50 años de estabilidad. En el siglo XIX: guerras civiles en la post-independencia, y en 1829, 1851, 1859, 1891. Desde este último hito hasta la intervención militar de 1924 transcurrieron 33 años; después, tenemos un período de trastornos institucionales con dictadura incluida hasta diciembre de 1932. Desde 1933 hasta 1973 gozaremos de 40 años de estabilidad institucional. Un record bueno para América Latina, pero hasta ahí no más.

Detengámonos en esta aparente 'edad de oro' regida por la Constitución de 1925, que va del 33 al 73, en la cual todos los partidos asumieron alguna vez responsabilidades gubernativas y legislativas. Así como en este período hubo alternancia en el poder -todos, repito, en alguna ocasión gobernaron-, también hubo renovación periódica de los cargos públicos. Las normas que rigen la convivencia ciudadana por medio de la Constitución fueron respetadas. No es poco decir.

Sin embargo, en cuanto nos preguntamos por las garantías al ejercicio de las libertades públicas, allí comienzan los tropiezos.

Arturo Alessandri gobernó varios años con facultades extraordinarias otorgadas por el

\footnotetext{
* Historiadora

$\therefore$ Ponencia presentada al Congreso Mundial de Ciencia Política efectuado en Santiago de Chile en el mes de noviembre de 1999.
} 
Congreso donde contaba con mayorías. Esto significaba concretamente entregarle al Ejecutivo el poder para vigilar a las personas, trasladarlas dentro del país, arrestarlas en sus casas o en lugares que no fueran cárceles, suspender o restringir el derecho de reunión. restringir la libertad de imprenta y radiodifusión pudiendo ejercer la censura previa y prohibir la circulación de impresos, practicar investigaciones con allanamiento, decretar la vacancia de cargos públicos. Alessandri hizo uso de estas facultades tanto contra la prensa y periodistas que le eran adversos así como también contra dirigentes sindicales que promovían huelgas en áreas sensibles, y contra militares díscolos. También recurrió en varias ocasiones durante su mandato a la declaración de estado de sitio.

Además de lo anterior, a comienzos de 1937 se aprobó una legislación que sancionaba delitos contra la seguridad interior del Estado. la que permitía coartar las libertades públicas sin necesidad de recurrir a la aprobación del Congreso en cada ocasión. Simplemente se aplica la ley. Tanto Arturo Alessandri como Juan Antonio Ríos hicieron uso de la Ley de Seguridad Interior del Estado, y bajo González Videla fue reemplazada por la Ley de Defensa Permanente de la Democracia que proscribía al Partido Comunista y borraba a sus militantes de los registros electorales. De hecho 25.000 militantes comunistas, casi un $4 \%$ del electorado, fueron borrados del padrón electoral ${ }^{2}$ Esta proporción subía significativamente en distritos mineros, llegando, de acuerdo a informes diplomáticos, a un $29 \%$ en Sewell, 58\% en Lota. $34 \%$ en la oficina salitrera Pedro de Valdivia. 'Esta legislación rigió ininterrumpidamente durante 10 años, entre 1948 y 1958. E incluso durante su vigencia, bajo Carlos Ibáñez se recurrió adicionalmente al Estado de Sitio para restringir aún más las libertades públicas.

Si el record de nuestra democracia en materia de derechos ciudadanos es bastante menos brillante de lo que se ha supuesto, veamos cómo nos desempeñamos en la cuestión de la representatividad del sistema político.

Desde 1874 existió en Chile el sufragio universal masculino y desde entonces hasta 1973 , el sistema proporcional que permite la representación parlamentaria de las minorías. Hubo que esperar, sin embargo, hasta mediados del siglo XX para que las mujeres pudiésemos ejercer plenamente nuestros derechos ciudadanos, participando por primera vez en una elección presidencial en 1952 y en una parlamentaria en 1953.

El sufragio universal masculino ponía como únicos límites la mayoría de edad y el saber leer y escribir. Este último requisito no fue menor. Aunque la tasa de analfabetismo fue bajando durante el siglo, inicialmente fue alta: sobre un $25 \%$ en las décadas de 1930 y 1940 , disminuyó al $20 \%$ en los años 50 , se mantuvo sobre el $15 \%$ en los 60 y sobre el $10 \%$ en los 70.

La inscripción en los registros electorales no fue obligatoria hasta 1962, y la proporción entre la población con derecho a voto y los inscritos inicialmente fue baja, aunque en continuo aumento: un $23 \%$ en los años $30 ; 32 \%$ en los $40 ; 40 \%$ en los $50 ; 50 \%$ en los 60 y $80 \%$ en los 70 luego que se ha hecho obligatoria la inscripción.

De allí la baja proporción de inscritos en relación a la población del país en los inicios del período, para aumentar explosivamente entre 1960 y 1973. Ésta fue de apenas el $9 \%$ en los años

1 Véase Germán Urzúa Valenzuela. Historia Política de Chile y su evolución clectocal (desde 1810 a 1992 ) Editorial Jurídica de Chile. Santiago 1992. Púginas $487-488$ : 571

2 Los datos se encuentran en Ricardo Cruz-Coke. Historia Elechoral de Chile 1925-1973. Editerial Juridica de Chile. Santiago. $108+$ Paginas 32 y 38

- De Allan Stewart al Departamento de Estade. Amemcan Embassy. Santiago enero 9 de 1950. Despareh N" 17. NA. DS.

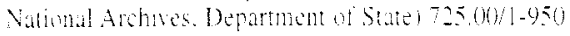


30 , subió al $11 \%$ en los 40 . El sufragio femenino vuelve a levantar la proporción: cercana al $18 \%$ en los años 50 , se va empinando al $20 \%$ en los inicios de los 60 . Con la inscripción obligatoria desde 1962, la proporción sube del 30\%, para llegar en 1973 al $44 \%$ cuando se ha permitido el voto de analfabetos y se ha disminuido los requisitos de edad a los 18 años. En cifras absolutas estamos hablando de un electorado que sube de menos de 700.000 inscritos a fines de los años 40, a 1.800 .000 al comenzar los años 60 , cerca de 3.000 .000 a mediados de esa década, 3.500 .000 en 1970; hasta 4.500 .000 en $1973^{4}$.

Este electorado tan pequeño en los años 30 y 40 al cual se suma el voto de las mujeres en los 50 , ¿ejercía sus derechos políticos libre e informadamente? Todos sabemos que la respuesta es negativa.

En las ciudades se practicaba el cohecho, es decir había un mercado de votos, con oferta y demanda incluida. La proporción de votos cohechados no era baja: en 1938 la Embajada Británica calculaba que en la elección presidencial de ese año un $22 \%$ de los votos serían comprados. ${ }^{5}$ Con muy pocás excepciones todos los partidos cohechaban: derechas y radicales de seguro. Por ejemplo, para una elección complementaria para Senador por Santiago en 1950, la Embajada de Estados Unidos calculaba que el candidato de derecha gastaría 18 millones de pesos y el de la combinación de gobierno (por entonces radicales, socialistas y socialcristianos), 13 millones. Se pagó entre 200 y 300 pesos por voto, de acuerdo a la misma fuente. ${ }^{f}$ Para tener una referencia, en esa misma fecha los precios de camisas de hombre fluctuaban entre 240 y 750 pesos, un vigésimo de la Polla costaba $\$ 75$ y el entero $\$ 1550$, un libro editado en Chile valía entre $\$ 60$ y $\$ 160$ mientras que la revista Peneca costaba $\$ 4 .^{7} \mathrm{El}$ cohecho. más que un 'vicio' es conveniente analizarlo como parte constitutiva del sistema electoral chileno hasta mediados del siglo XX. Por lo mismo no faltaron quienes plantearon públicamente en ese entonces que constituía un correctivo al sufragio universal.

Sólo la reforma electoral de 1958 que estableció la cédula única puso fin definitivamente al cohecho pues impidió conocer la forma cómo se había votado y controlar así la efectividad de la operación de compra-venta del voto. A partir de entonces los gastos electorales se derivaron integramente a propaganda.

Adicionalmente, en el mundo rural el voto del inquilino era prácticamente un voto cautivo. En las haciendas del Valle Central hasta bien entrada la década del 50, la autoridad del patrón no tenía casi contrapeso. Sin radio ni buses rurales, el inquilino poco sabía del mundo exterior, y menos de los altibajos de la política criolla. El patrón, acostumbrado a recibir de parte del inquilino obediencia y lealtad, le entregaba listo el voto que éste habría de poner en la urna; recordemos que estamos hablando del periodo anterior a la cédula única. Muchas veces, se festejaba por idelantado el triunfo del candidato patronal, en todo caso, se esperaba como recompensa una fiesta, empanadas, asados, junto a algún discurso para acentuar la bondad de la opción electoral escogida."

La ausencia de cohecho rural nos está señalando la inexistencia de un mercado del voto,

- Todas estas cifras se encuentran en Ricardo Cruz-Coke. Op. cit.. páginas 37 y 38.

$=$ De Sir C. Bentinck a Viscount Halifax. Despatch $x^{\circ}$ 102. Santiago. 26 de abril de 1938. Fo. (Foreign Office) $371-21437 \mathrm{~A}$

$3536 / 571 / 9$.

De Charles C. Hall al Departamento de Estado. American Embassy. Santiago 14 de diciembre de 1950. Despatch No 561 . NA.

DS. $725.00 / 12-1450$.

Zig-Zig N 2379.28 de octubre de 1950.

- Véase Rafael Agustín Gumucio. Apuntes de medio siglo. Santiago. 1994. página 120; y Germán Urzúa Valenzuela. op. cit. paginas $507-508$

Esta información está respaldada por una serie de entrevistas realizadas a personas del mundo rural que visieron en las decadas anteriores a la reforma agraria como parte de un provecto financiado por la Dirección de Investigaciones de la Universidad de Santiago de Chile. que lievé a cabo entre 1996 y 1998. 
donde el elector podía eventualmente escoger entre diversas ofertas electorales, Que el voto del inquilino era patrimonio del terrateniente se nota en la elección parlamentaria de 1945 en la provincia de Colchagua: de los 10 candidatos que se presentaron fueron elegidos los dos que llevaba el Partido Conservador, uno del Partido Liberal y el único candidato del Partido Radical; los partidos Democrático. Socialista, Socialista Auténtico y Falange Nacional no lograron elegir a ninguno de sus candidatos; en conjunto Conservadores y Liberales sumaron 9.307 votos, mientras que la suma de votos de los dos partidos Socialistas llegó a tan solo 358 preferencias. $^{10}$

Si el voto libre e informado constituía una cierta rareza, el principio de un hombre un voto también se veía alterado por la sobre representación de las áreas rurales, pues estas circunscripciones elegían proporcionalmente a su población un mayor número de parlamentarios que las zonas urbanas.

Y sin embargo, a pesar de todas estas distorsiones en la representación popular, la clase política con poder en el Legislativo y en el Ejecutivo contenía en si toda una amplia gama social, desde obreros a empresarios. y a todo el espectro ideológico desde Comunistas hasta Conservadores, y en su momento incluso Nacional-Socialistas. Como decíamos inicialmente en estos 40 años que van desde 1933 hasta 1973. todos los partidos, en alianza o por sí solos, en algún momento lograron acceder al poder Ejecutivo, y por cierto también al Legislativo. La efectividad de la competencia por el poder sí que fue una característica distintiva del sistema político chileno.

Ahora bien. no podemos concluir nuestra caracterización de la democracia chilena a mediados de este siglo sin referirnos a la representación corporativa que existía paralelamente a la representación electoral en el sistema político. En efecto, las cuatro asociaciones empresariales decimonónicas -SNA. SFF, SNM y Cámara Central de Comercio- estuvieron desde la década de 1920 representadas en los organismos estatales encargados de la administración y reglamentación económica y social. Esta era una práctica tan extendida que, por ejemplo, en 1964 la SFF nombraba directores en 20 agencias gubernamentales y en 8 consejos asesores del gobierno. ${ }^{11}$

De modo que no sería exagerado concluir que la estabilidad institucional del período posterior a 1933 descansaba justamente sobre las mismas limitaciones del sistema representativo, en un equilibrio sumamente frágil de las fuerzas sociales y corrientes ideológicas en competencia. Ahora bien, en la medida en que dichas restricciones fueron desmanteladas por la misma clase política en la segunda mitad de la década de 1960, -pensemos tan sólo en el universo electoral que crece más de un $640 \%$ entre fines de los años 40 y principios de los 70 , sin revolución de por medio-, el frágil equilibrio se rompió, las demandas sociales se multiplicaron a la vez que se expresaron directamente sin canalización institucional, y el régimen colapsó.

La democracia que tuvimos contenía por tanto limitaciones sustantivas. Tal vez la democracia que tuvimos no es sino la democracia que no fue.

10) Lus datos se encuentran en el Anurio Estadistico de 1945 ditado por ha Dirección Gemeral de Estadisticas.

If Constantine Meness. Public Policy and Organized Buinese in Chile: A Preliminary thalysis'. Joumal of Intemational

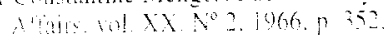

